\title{
Aspectos políticos das reformas da instrução pública na cidade do Rio de Janeiro durante os anos 1920
}

André Luiz Paulilo Universidade de São Paulo

\section{RESUMO}

$\mathrm{O}$ artigo analisa as relações que a administração pública pode estabelecer com os saberes escolares e as práticas educativas utilizando-se dos documentos oficiais das reformas da instrução pública realizadas no Rio de Janeiro durante a década de 1920. Examina as dimensões política e social das reformas de instrução, discute os problemas envolvendo o estabelecimento de critérios para definir estratégias de ação no sistema público de educação e outras tendências da historiografia na abordagem do tema. Finalmente, este artigo enumera algumas perspectivas abertas por aquelas reformas.

Palavras-chave: História da educação. Instrução pública. Reforma educacional.

\begin{abstract}
The article analyses relations which public politics of education were able to establish during the 1920's from Rio de Janeiro city with regard to scholar knows and educative practices, using officials data about instruction reforms in the 1920's from Rio de Janeiro. It examines political and social dimensions of instruction reforms, discusses problems involved in establishing criteria to define strategies of action in public system of education and other historiography tendencies related to the theme. Finally, this paper lists perspectives opening at those reforms.
\end{abstract}

Keywords: History of education. Public instruction. Educational reform.

Seria de se desejar que se pudesse dar início a uma reflexão sobre as reformas da instrução pública no Distrito Federal durante a Primeira República por um balanço de suas realizações: atualização das referências teóricas da pedagogia ensinada nas Escolas Normais e das práticas escolares utilizadas no sistema de ensino público, modificação dos programas escolares nos diversos níveis do ensino municipal, promulgação de uma nova legislação de ensino para a capital, organização de amplos serviços de assistência social e medicina preventiva e construção de novos edifícios escolares, entre outras iniciativas. 
Entretanto, não me parece prudente começar dessa maneira: os resultados a que chegaram as reformas da instrução pública foram por demais localizados em algumas escolas e restritos à supervisão moral e organização do trabalho escolar para justificar as relações que se estabeleceram entre os diversos elementos da escola com a sociedade e, portanto, para compreender sua dimensão histórica. Eis porque a primeira parte deste estudo será dedicada à caracterização do modo como aparece o tema da educação popular nas reformas da instrução pública realizadas na cidade do Rio de Janeiro durante a década de 1920. Desejaria mostrar que mais que a ordem escolar, foi a ação política o alvo dessas reformas. Foi a política a área na qual se tornou evidente o caráter pluridimensional da instrução pública no início do século XX.

Contudo, em vez de um jogo de alianças políticas que levasse ao confronto direto com o poder oficial no combate pela remodelação do aparelho pedagógico da capital, seus responsáveis preferiram iniciar as escaramuças num terreno mais favorável aos seus programas de reforma social: o técnico. A ele será consagrada a segunda parte deste estudo. A interpretação do modo como o discurso acerca das práticas pedagógicas foi utilizado nas reformas da instrução pública será a chave de toda a minha reflexão: procurarei mostrar que o escolanovismo, na reforma do ensino público carioca, foi ao mesmo tempo um intento pedagógico e um lance político, uma estratégia de ação. $\mathrm{O}$ desejo é demonstrar essa simultaneidade como um ponto de ambigüidade do processo de reforma do aparelho pedagógico da capital federal, para só então empreender uma interpretação do modo como o enunciaram.

Os nódulos de minha análise seriam pois: a pluralização das funções da escola pública dentro da organização social da cidade do Rio de Janeiro e o caráter ambíguo do processo de reforma do ensino. Talvez o leitor, ou a leitora, já esteja a objetar que o movimento reformista da educação, conhecido pelas primeiras décadas do século passado, estará assim misturado de modo inextricável, neste texto, com as interpretações que lhes deram seus responsáveis diretos. Peço um pouco de indulgência, pois o objetivo destas reflexões não é outro senão questionar tais interpretações, decantar um pouco a mistura. Neste propósito, o significado político das reformas Carneiro Leão (19221926) e Fernando de Azevedo (1927-1930) configura o domínio principal do estudo acerca dos papéis que a educação popular desempenhou no processo de institucionalização da escola pública. 
REFORMAS EDUCATIVAS E SISTEMA PÚBLICO DE ENSINO: EDUCAÇ̃̃O POPULAR, PAPÉIS SOCIAIS E O PROCESSO DE INSTITUCIONALIZAÇÃO DE UM MODELO ESCOLAR

No domínio da história da educação, essa questão básica se apresenta com cada vez maior insistência hoje: o que revelam os documentos oficiais além das regulamentações institucionais e da convenção de um determinado momento? O problema que ela considera é útil aqui para conduzir a uma reflexão, ou mais exatamente, ao estado atual de uma questão hoje bastante fluida: a dos métodos de abordagem das políticas e das práticas de reforma educacional pela história.

Domínio em renovação nos últimos dois decênios, a história da educação conheceu uma importante multiplicação dos seus temas, sem contudo encontrar um consenso metodológico, o que não é de se lamentar. Porém, em meio a todas essas aberturas, importa perguntar sobre os modos dominantes de narrar na historiografia educacional. Isto é: de que modo a historiografia da educação vem delimitando e definindo suas questões, temas e objetos de investigação?

Neste trabalho não vou tomar essa questão senão como pano de fundo de uma interrogação limitada aos desdobramentos das reformas da instrução pública na cidade do Rio de Janeiro entre os anos de 1922 e 1930. Ocorre que não me parece prudente esquivar-se dela quando se deseja refletir acerca do significado político das ações organizadas, primeiro, por Antônio Carneiro Leão, e em seguida, por Fernando de Azevedo perante a Diretoria-Geral de Instrução Pública do Distrito Federal. Ainda que abordar as reformas educacionais do início do século a partir das fontes oficiais possa parecer uma grande ingenuidade, é desta forma que tratarei o tema aqui: forçarei uma porta escancarada de longa data, recordando que a visão de educação que emerge com o movimento renovador não é absolutamente a mesma do Império. Igualmente, noutro pólo, terei em vista uma leitura um tanto quanto "retrógrada", pois toda uma historiografia, nascida nos dias seguintes às reformas da instrução, e desenvolvida ao longo de pelo menos cinco décadas, concentrou sua leitura desses eventos na escolarização das classes populares sob o regime republicano.

Não penso nisso, entretanto, como um retroceder, mas como a retomada de um domínio pouco explorado dentro da história das reformas da instrução pública do início do século passado, suas estratégias de aculturação. Penso, assim, em responder às expectativas da historiografia atual que, como indica um dos títulos das pesquisas de Clarice Nunes, aponta para uma leitu- 
ra nova de velhos objetos ${ }^{1}$. Campo pouco explorado, mas já aberto, dispõe atualmente de importantes estudos do que se poderia tomar como as estratégias de aculturação, principalmente das classes populares, empregadas pelas reformas Carneiro Leão e Fernando de Azevedo. São por vezes estudos que marcaram época na historiografia do período, como Educação e sociedade na Primeira República, de Jorge Nagle, e Molde nacional e forma cívica, de Marta Carvalho, e por outro lado, estudos recentes como as discussões realizadas sobre a modernidade educacional por Clarice Nunes, em A escola redescobre a cidade: reinterpretação da modernidade pedagógica no espaço urbano carioca (1910-1935), e as análises de Diana Gonçalves Vidal sobre as práticas de ensino no início do século $\mathrm{XX}^{2}$. De todo modo, é preciso ainda chegar a um acordo preliminar sobre o que se poderia denominar estratégias de aculturação.

Uma primeira delimitação dessa denominação pode ser feita considerando os apontamentos que Jorge Nagle faz sobre o que convencionou chamar de "entusiasmo pela educação" e "otimismo pedagógico." Seu estudo sobre o clima em que as reformas educacionais operaram, a partir de 1920, é muito importante, e ainda que ele incorra num certo determinismo sociológico, consolidou essa nomenclatura para distinguir momentos diversos das discussões em torno da organização de um modelo de escolarização pública. Do investimento na multiplicação das instituições escolares e da educação escolar às formulações doutrinárias sobre a escolarização, Nagle acompanha a maturação de uma atitude de valorização do tema da instrução, dos processos de escolarização que procura e encontra suas formas de intervenção, ora como parte da solução dos grandes problemas nacionais (entusiasmo pela educação), ora se restringindo a formulações puramente educacionais ou pedagógicas (otimismo pedagógico). Foi um clima que favoreceu a mudança dos padrões de ensino e cultura nas instituições escolares, em diferentes modalidades e em diferentes níveis. Nele os procedimentos de disseminação da educação popular decidiram-se pelo caráter obrigatório do ensino primário, pela difusão do ensino técnico-profissional, pela insistência num programa de ensino prático, instrumental e vocacional.

Essa procura das atitudes que levaram à reestruturação do funcionamento escolar não deixa, contudo, de determinar questões maiores. A luta pela difusão do ensino primário, segundo a interpretação de Vanilda Paiva, pode ser vista como a contrapartida educacional da mobilização intelectual da época:

(...) todos os que se preocupam com o problema educacional congregam-se contra o tradicional, contra o velho, representado naquele momento pelo clero dedicado à educação das elites, preocupa essencialmente a educação do povo em oposição à educação das elites. ${ }^{4}$ 
A oposição evidente de uma sociedade firmemente hierarquizada responde aos movimentos de reivindicação sociais dos anos 1910 e 1920. Vanilda Paiva propõe, a esse respeito, algumas hipóteses, que no entanto não distinguem das disputas em torno da recomposição das estruturas educacionais do período as estratégias de aculturação das camadas populares em jogo. Pressupõe que a educação popular é aquela oferecida a toda a população, aberta a todas as camadas da sociedade, e por isso gratuita e universal, ou então, aquela destinada às camadas populares da sociedade, isto é, o ensino primário e o ensino profissional. É a partir dessa limitação institucional que avalia o papel que tiveram para os "entusiastas da educação" a posição nacionalista em educação, o ruralismo pedagógico, as preocupações qualitativas do ensino e seu humanitarismo. Reencontra-se nessa interpretação a mesma oscilação identificada por Jorge Nagle nas formas de intervenção administrativa nos processos de escolarização articuladas pelas reformas educacionais no início do século passado, isto é, ora como parte da solução dos grandes problemas nacionais, ora restritos a formulações puramente educacionais ou pedagógicas, ou, como sistematizou Vanilda Paiva em sua análise, entre uma perspectiva interna e outra externa da educação ${ }^{5}$.

Essa primeira exploração nos domínios das estratégias de aculturação dominantes nas reformas educacionais é importante: ela evita as armadilhas de uma história da educação concebida como história das idéias educacionais ou da pedagogia, sem referências às exigências da investigação histórica das estruturas políticas e da conjuntura social vigentes. Critica-se, todavia, que ela atinge apenas um único nível, essencialmente sociológico, dos procedimentos de aculturação produzidos pela escolarização, que se exprime nas estratégias de difusão, imposição e apropriação de novos saberes pedagógicos e de novas práticas escolares.

É forte o ímpeto de identificar um outro nível mais secreto desses procedimentos, que além dos processos técnicos já propriamente reformistas, seria também revelador do seu significado político, não só de uma visão transformada da educação e da sociedade, mas dos seus custos, ou seja, de suas implicações. Ele é semelhante à ambição que se propusera Marta Maria Chagas de Carvalho quando escreveu sua tese de doutorado. Mais exatamente, passar da elaboração sociológica do entusiasmo pela educação à descrição do arsenal autoritário envolvido nos projetos de homogeneização cultural e moral postulados por um grupo de intelectuais que se auto-representou como elite $^{6}$. Passagem que lhe permitiu identificar, sob forma concentrada mas muito sugestiva, o universo de representações sociais contidas no ideário e na ação educacional dos anos 1920. Seu inventário engloba as três dimensões mais importantes do debate educacional da Primeira República, a moral, a higiene 
e o trabalho. De um lado, uma vasta empresa de moralização das práticas de vida e lazer do operariado e da população improdutiva, das mulheres e da infância segundo os códigos da ciência, da técnica e do progresso. De outro, a elaboração de uma hegemonia cultural organizada sob o modelo da fábrica. Todos esses processos põem em perspectiva uma quantidade de informações e traços que, acredito, conduzem a níveis de representação diferentes: entre a proclamação direta ou o discurso oficial por meio do qual a visão de educação dessa "elite" se faz conhecida, e a maneira pela qual foram difundidos, impostos ou mesmo vividos seus valores, foi mobilizado todo um arsenal de procedimentos de controle social sobre os quais é preciso refletir, mas que já se pode perceber, com alguma segurança, como pertencentes ao projeto de modernização adotado pelas reformas educacionais de então.

Eis aí uma perspectiva importante ao entendimento das políticas públicas de educação desenvolvidas no espaço urbano carioca da época. Isto não significa lançar um olhar crítico aos estudos que tomaram como objeto de suas análises as relações entre a vida escolar e o cotidiano urbano. Mas de assinalar no capítulo "História das reformas educacionais na Primeira República" que os estudos acerca das estratégias, dos mecanismos e dos procedimentos mobilizados pelo poder público para promover a homogeneização cultural e moral da população dificilmente ultrapassam os domínios de uma história social da cultura escolar. Isto é notável mesmo em meio às análises que reputam grande importância aos dois extremos da questão, vale dizer, a economia, a sociedade e a cultura, de um lado, e a educação das camadas populares, de outro. Carlos Monarcha, por exemplo, não encontrou lugar para essa discussão em sua pesquisa: "A reinvenção da cidade e da multidão: dimensões da modernidade brasileira — a escola nova”, ainda que sua problemática a solicitasse, qual seja, " a dimensão práxica de um pensamento contra-revolucionário que procurou estabelecer, através do discurso científico, a menoridade racional do proletariado urbano"7. Na tese de livre docência de Clarice Nunes, um vasto espaço está reservado, ao longo de um raciocínio analítico, às estratégias de aculturação praticadas pela escola: as normas de higiene, as mensurações das faculdades mentais via testes psicológicos de inteligência, aptidão e personalidade, e a conseqüente distribuição dos alunos na rede de ensino pública em função dos resultados obtidos nesses testes, a padronização do equipamento escolar, as festas e exposições, entre outros. Nele, entretanto, ela não favorece uma discussão do significado dessas estratégias para a organização de um sistema público de ensino, na medida em que encaminha suas reflexões para a nova leitura do urbano paulatinamente construída pelo esforço reformador de toda uma geração de educadores, e não para as políticas oficiais de educação forjadas no interior da Diretoria da Instrução Pública. 
Longe de ser o indício de uma lacuna nos estudos de história da educação, esse limite metodológico indica as dificuldades para alcançar, além do discurso e da operosidade das elites, também o conhecimento das populações anônimas, essas que não tiveram, como indica Michel Vovelle, o luxo de uma representação individual, por menor que fosse ${ }^{8}$. Nesse aspecto, ela reflete o estado atual de pobreza das fontes relativas às formas de educação praticadas pela parcela pobre da sociedade carioca aos códigos de sua sociabilidade ou mesmo às suas aprendizagens. $\mathrm{O}$ que a história tem, e por vezes insiste em chamar de educação popular, é o produto negativo de um sistema de invalidação. Ele é explicito na descrição que Miguel Couto dá do analfabeto:

(...) O analfabetismo não é só um fator considerável na etiologia geral das doenças, senão uma verdadeira doença, e das mais graves. Vencido na luta pela vida, nem necessidades nem ambições, o analfabeto contrapõe o peso morto de sua indolência ou o peso vivo de sua rebelião a toda idéia de progresso, entrevendo sempre, na prosperidade dos que vencem pela inteligência cultivada, um roubo, uma extorsão, uma injustiça. Tal a saúde da alma, assim a do corpo; sofre e faz sofrer; pela incúria contrai doenças e pelo abandono as contagia e perpetua. ${ }^{9}$

Esse texto é importante por dois motivos. Em primeiro lugar, em que pese o simplismo com que avaliava a ordem social estabelecida, entendia a escolarização como o único e grave problema da nacionalidade. Nessa perspectiva, a instrução, o ensino e a escolarização eram pensados como instrumentos para generalizar as práticas higienistas e reduzir as conseqüências sociais da pobreza. Era em função do seu caráter regenerador que eram defendidos, o texto representava uma amostra das bases em que se assentavam as discussões acerca da difusão do ensino elementar. Em segundo lugar, porque não hesitava em tornar a educação o vetor de certezas militantes. Sublinhava, ao contrário, que difundir a educação a toda população era sim ajudar o seu enraizamento, o seu civismo, mas sobretudo assegurar sua sobrevivência. A ordem social justifica o zelo remodelador e planificador da opção: tratava-se de um programa de assimilação cultural firmemente ligado à tarefa de homogeneizar as referências sociais do País.

Miguel Couto não é de modo algum um exemplo isolado. Pelo contrário, atua no mesmo contexto intelectual compartilhado por Carneiro Leão e Fernando de Azevedo. São expressivas as preocupações que Carneiro Leão nutria perante o estado da cultura nacional em 1917, por exemplo, época em que publicou O Brasil e a educação popular:

(...) ainda vivemos nos tempos de esperar milagres. Supomos que a nossa forta- 
leza se fará com decretos e medidas de economia se o povo continua o mesmo, se perseveramos na mesma falta de capital e trabalho se não há iniciativa, se a aspiração nacional pela burocracia não descontinua um momento ${ }^{10}$.

Contemporâneo da obra de Carneiro Leão é o texto $D a$ Educação Física, de Fernando de Azevedo, onde se pode ler acerca das condições de vida da população pobre das capitais brasileiras:

(...) Não é preciso carregar as cores já negras a este quadro de miséria social e física da classe desfavorecida da fortuna, nos grandes centros, para onde emigra a população rural em busca de salário mais elevado. Aí nessas cidades industriais e superpovoadas vivem as crianças na promiscuidade das ruas insalubres ou de cortiços malsãos, onde, a preço da saúde, se vão os meninos iniciando na vida de tunantes, que o meio fomenta, e na prática de vícios, que o mau exemplo estimula, quando a educação física popularizada, ao alcance de todos, poderia transformar essas pequenas células sociais em preciosos elementos de energia e trabalho. ${ }^{11}$

De um modo geral a preocupação com a educação popular pode ser interpretada como a manifestação do desejo de construir uma unidade fundamental para a nação. Nada o demonstra mais claramente do que os empreendimentos realizados pelas reformas educacionais na década de 1920. A documentação que essas administrações reuniram é portadora dessa forma de entendimento. Trata-se de relatórios administrativos, monografias descritivas, documentos estatísticos, correspondência oficial, por vezes oficiosa, artigos de periódicos, relatos de reforma e compêndios de pedagogia que, apesar de variados, apresentam alguns aspectos em comum. Revelam o reconhecimento de uma cultura diferente, alheia às formas de profissionalização capitalista. Assumem, de forma geral e pouco explícita, o discurso da exclusão social para qualificar ou desqualificar práticas em termos de posicionamento social. E, ainda, insinuam a redescoberta dos estratos do passado que dariam coerência aos esforços de construção de uma unidade fundamental para a nação. Três modos de interpretar são sobrepostos, portanto: oposição, desqualificação, aculturação.

São os modos como também o historiador apreende as tensões resultantes do processo de escolarização institucionalizado durante as décadas republicanas. Interrogar a historiografia sobre esse ponto é o mesmo que se defrontar não com um projeto de educação popular, mas com vários. Muito se tem escrito sobre três deles: o liberal, o católico e o socialista. Em que pese a heterogeneidade que caracteriza não só os estudos mas os projetos mesmos 
que se registram sob a rubrica de tais tipos "partidários", trata-se de interrogações sobre sistemas de controle ideológico e político presentes nas diferentes propostas de reforma do aparelho pedagógico da capital no período. São estudos sobretudo empenhados na descrição das coesões sociais preocupadas em assegurar ao País a transmissão de um misé en valeur às jovens gerações: os liberais, seu "cientificismo" ideológico ${ }^{12}$; a igreja, seus dogmas ${ }^{13}$; os socialistas, sua "ideologia" cientificista"

De qualquer maneira, é um período no qual surgem novas instituições, cuja organização administrativa revela os objetivos científicos recentemente estabelecidos. Os métodos ativos de educação tinham já inspirado os docentes da Escola Normal a operacionalizar o ensino por meio do conhecimento cumulativo e classificatório da atividade das crianças: toda informação sistemática poderia então ser considerada como contribuição para o inquérito coletivo concebido para sistematizar a instrução pública segundo regras padronizadas. As reformas educacionais dotaram estas realizações de uma estrutura de sociabilidade intelectual e de uma posição política definida pela difusão do ensino primário obrigatório, gratuito, unificado e leigo. As reformas Carneiro Leão e Fernando de Azevedo partilharam a tarefa de normalizar, codificar, profissionalizar e sistematizar a escolarização das camadas populares, e tudo isso foi usado para estabelecer o âmbito e os critérios da educação a elas dispensadas. Em conseqüência, fica delineado um sistema de ensino dirigido e controlado para dar conta do atraso intelectual identificado na população pobre e de sua resistência às inovações.

Como um problema propriamente político, a organização de um sistema público enraizado nessa convicção acerca das populações dos subúrbios cariocas interveio não somente numa realidade imóvel ou residual, atrasada, cuja sociabilidade provocava interrogações morais, como fazem pensar os textos produzidos pelos gabinetes da Diretoria-Geral de Instrução Pública. Ela atingiu também um conjunto de atitudes e comportamentos, uma sociabilidade dinâmica tanto expressa na musicalidade dos subúrbios quanto fundada na inversão de valores e hierarquias, na corrosão do riso e da festa encontrada na contraleitura da ordem oficial praticada nos dias de carnaval ou na própria religiosidade cotidiana. Recobriu, por isso, uma visão de educação maciçamente incorporada por estruturas organizadas para mediar um conjunto de comportamentos e relações sociais definidos não só pela carência material ou ausência política, mas principalmente pela degeneração moral do povo.

Uma tal visão de educação expressou uma maneira de perceber e construir o social. As iniciativas de renovação da instrução pública, mas também a pena de diversos intelectuais comprometidos com a "causa educacional" 
buscaram confirmar politicamente um princípio de ordem social simultaneamente fundamental para a organização da cultura e unificador do sentido de nacional, isto é, conceber e institucionalizar, pedagógica, política e juridicamente, um sistema de educação pública que exprimisse um programa de "organização nacional pela organização da cultura", como bem observaram Marta Carvalho, Maria Cecília Cortez de Souza e Carlos Monarcha ${ }^{15}$. Nesses domínios dos documentos oficiais do gabinete de instrução e das publicações sobre esse tema, tudo atesta a importância desta visão de educação para consubstanciar uma forma de se utilizar o sistema escolar para fins de disciplina, de economia ou de Estado adaptados àquele programa.

Como se sabe, pelos estudos de Maria Lúcia Hilsdorf e Roque Spencer Maciel de Barros, essa prática está longe de ser uma novidade do século XX. No momento em que se inicia a condenação da falsidade do sistema representativo do Império, a instrução pública foi rapidamente alçada como o ideal por excelência da sociedade democrática. Tanto os liberais quanto os republicanos não pararam de o recordar: para eles não haveria democracia sem instrução dilatada; ao futuro pela escola, diziam republicanos e liberais de diferentes matizes ${ }^{16}$, igualmente não seria possível reagir perante o "atraso" do ambiente, a "miséria" e a "fraqueza" da raça ou realizar qualquer obra de renovação nacional ${ }^{17}$. Eram referências que serviam para consubstanciar uma forma de uso do aparelho de ensino cuja finalidade era a produção/reprodução de uma outra ordem. Acima daquilo que dividia uns e outros, postulavam, em princípio, uma concepção da instrução como índice do progresso. Essa relação era polêmica, cheia de matizes, e tinha seus temas obrigatórios: punha em causa a organização do ensino elementar, profissional e secundário, a educação popular, o ensino religioso, as iniciativas de controle oficial da instrução pública, as práticas e os métodos de ensino, e também todo o alcance político dessas questões.

O movimento de reforma da instrução pública na década de 1920 veio sobrepor a essa polêmica, muitas vezes ruidosa, um novo tipo de problemática no já problemático processo de atualização do País. Utilizou largamente o mesmo repertório temático, mas inscreveu-o num quadro de referências bastante diferente. Três convicções principais orientaram esse movimento no Distrito Federal. A primeira proclamava a urgência em dar ao trabalho e à técnica um lugar proeminente entre os valores educacionais. As condições efetivas do mercado de trabalho e dos processos de produção numa economia capitalista parecem ter dominado muitos traços das propostas de reforma educacional. Mesmo quando se tratava de induzir diferenças determinantes na função social de cada nível do ensino, como ocorria em relação à escola primária, profissional e normal dentro do modelo de escolarização desejado 
para a cidade do Rio de Janeiro, insistia-se na importância da educação pelo trabalho e da aprendizagem de uma técnica profissional para todos aqueles que passassem pelo sistema público de ensino. A segunda, por conseqüência, opunha a organização dualista do aparelho pedagógico _ que reservava o ensino primário e profissional às classes empobrecidas __ perante um sistema de ensino que assegurasse a unicidade inicial da educação pública para as camadas populares e abastadas, segundo os princípios de uma sociedade meritocrática: "homens novos para tempos novos", dizia Fernando de Azevedo ${ }^{18}$. Nesta reordenação da demanda escolar, que estendia a escola para os subúrbios cariocas procurando absorver sua população no ensino oficial, a interiorização das normas e a reprodução dos comportamentos desejados ocupavam um lugar estratégico. Não apenas porque assegurariam a ordem social, mas mais ainda porque representavam um prolongamento do processo civilizador reivindicado pelas reformas educacionais. Para essa demanda, tal processo foi apresentado, mais modesto e mundanamente, como uma tarefa de moralidade, de aquisição de maneiras educadas e respeitáveis, de novos padrões de limpeza e correção, de etiqueta sexual e de conduta adequada em público. Foi sobre esse projeto de regeneração da sociedade pela reforma do homem que se articulou a terceira convicção, a de que a educação era não mais indício, mas fator constitutivo da sociedade como nação. Com efeito, o nacionalismo que a sociedade conheceu na década de 1920 foi um programa de engenharia social preocupado em assimilar os estranhos étnicos, religiosos ou lingüísticos. Esse imaginário foi capturado pelas reformas da instrução pública, fazendo crer que por meio de uma escolarização sistemática de toda a população, deixaria de haver estranhos no mundo cotidiano dos cidadãos residentes transformados em patriotas.

Esse fundo de convicções alimentou as estratégias de aculturação sistematizadas pelas reformas da instrução pública no aparelho de ensino da capital com seu conteúdo. Deu expressão ideológica às pretensões das administrações Carneiro Leão e Fernando de Azevedo de fazerem o sistema público de ensino representar uma espécie de matriz social essencial, que distribuiria os indivíduos ao longo dos processos de trabalho e produção a partir do mérito e do dom de cada um. Seria função da escola, segundo essa forma de pensar na educação, identificar a vocação de cada um e medir sua competência ou mérito a fim de garantir a socialização das vontades individuais nas diferentes dimensões da vida coletiva. Assim, as iniciativas que entre 1922 e 1930 asseguraram para o sistema público de ensino as tarefas de vigilância, controle e correção da escola, assumiram a dimensão política da educação popular como um eixo da organização social, fizeram parte de uma profissão de fé sociológica: 
(...) Aplicar as medidas mais apropriadas para que a educação responda positivamente aos ideais sociais; estimular o magistério para as obras de cooperação em proveito da comunidade, de que ele extrai a sua autoridade e a sua força; associar os pais e os professores, para o ideal comum de educação dos filhos, no lar e na escola; estabelecer uma compreensão recíproca entre a escola e as organizações que tomem parte efetiva na realização dos fins que prossegue a obra educacional; contribuir para o estabelecimento de cooperativas escolares de consumo e de produção, para reduzir o custo do material escolar; e, enfim, verificar e coordenar todos os elementos que formam a agência social educativa e correspondam ao interesses e legítimas aspirações da comunidade; tal é a tarefa que desse ponto de vista incumbe à escola, inspirada num amplo espírito de cooperação e serviço social, e que não lhe é possível desempenhar, senão transformando a sua estrutura na direção em que se podem legitimamente esperar um aumento de sua eficiência social e, portanto, um desenvolvimento maior de seu raio de ação ${ }^{19}$.

Foi em nome dessa pluralidade de dimensões envolvida na problemática educacional que foram instituídos sucessivamente um repertório atualizado de referências teóricas da pedagogia para o ensino nas Escolas Normais e de práticas escolares para uso no sistema de ensino público; novos programas escolares nos diversos níveis do ensino municipal; uma nova legislação de ensino para a capital; amplos serviços de assistência social e medicina preventiva; bem como uma política de construção de novos edifícios escolares. Esse feixe de iniciativas levou a pôr em causa a organização de um sistema unificado de educação nacional e a apresentar, acerca do modelo de escolarização, problemas sobre a formação dos corpos e da mentalidade por dispositivos materiais de controle e disciplina. Sensibilizaram um público profissional com práticas de aculturação diversificadas que, não só no fazer administrativo, mas principalmente com os procedimentos detalhados na legislação estipularam regras e obrigações sobre as diferenças de conduta responsáveis por separar, classificar e organizar os indivíduos; definiram dentre o repertório de conhecimentos especializados e disponíveis aqueles que melhor representavam o que se entendia como experiência humana; reformularam diversas questões sociais e culturais como problemas de eficiência e eficácia. A reforma educacional associava-se decididamente com um saber profissional, a escola pública consolidou-se como função de Estado na consecução do progresso nacional e a individualização da pessoa deu-lhes uma determinada forma institucional mediante a prática pedagógica. A eficiência desse modelo escolar talvez não tenha sido determinante na década pré-revolucionária. Mas não poderia ser esquecido no processo de gestação do Ministério de Educa- 
ção e Saúde no governo Getúlio Vargas e, sobretudo, na disputa que se sucedeu entre católicos e liberais na definição de uma política nacional de educação. Por fim, essas iniciativas puderam ser o lugar de uma transformação decisiva: a que fez da educação um valor constitutivo da nacionalidade e um jogo de representações sociais.

\section{PERTINÊNCIA E AMBIGÜIDADES DO TERMO ESCOLA NOVA: PODER, SABER E ESCOLARIZAÇÃO NAS POLÍTICAS PÚBLICAS DE EDUCAÇÃO NO INÍCIO DO SÉCULO XX}

Na história das reformas da instrução pública, isolar as administrações Carneiro Leão e Fernando de Azevedo parece ser um artifício contraproducente quando importa pôr em contexto seus repertórios de ação. No entanto, a transformação do estatuto político da educação popular faz da distinção entre as reformas Carneiro Leão e Fernando de Azevedo um instrumento analítico significativo para perceber a dinâmica social dos procedimentos de modificação do trabalho educativo no período. Entre tantas idéias e ações que relacionavam a administração Carneiro Leão à administração Fernando de Azevedo, e vice-versa, a organização dos significados das ações de reforma indicaram opções distintas. Se Antônio Carneiro Leão foi recalcitrante quanto à conveniência de organizar o sentido de suas iniciativas em função de uma apologia do novo, preferindo insistir na capacidade dos processos de observação e na experiência para lidar com as realidades escolares, novas e tradicionais ${ }^{20}$, Fernando de Azevedo rapidamente procurou inscrever o novo código de ensino, que conseguira aprovar no Conselho Municipal para regulamentar a reforma da instrução pública, dentro da corrente escolanovista. É dizer que associou ao conjunto doutrinário que organizava o Decreto $n^{-} 3.281$ de 28 de janeiro de 1928, um significado integrador da experiência e do conhecimento pedagógico para o quadro docente da capital capaz de modificar-lhe os valores da sua prática e do seu saber, e não só de lhe dizer as normas, as regras e os deveres. Fazendo-o, consolidou mais que um sentido para a reforma que implementava, um significado para o próprio termo escola nova.

A insistência de Antônio Carneiro Leão na implementação dos métodos ativos nas escolas públicas da capital federal trouxe exigências administrativas supletivas ao mero controle burocrático do expediente. Controlou a reestruturação das formas do ensino modificando os critérios de promoção do professorado e o repertório de referências nos programas escolares. Estabeleceu, por essa via, a discussão das propriedades do trabalho docente utilizando-se de comissões formadas por professores da Escola Normal. Nessas con- 
dições, a mudança se foi realizando por persuasão, por experimentação e por infiltração. Na administração da Diretoria-Geral de Instrução por Fernando de Azevedo, essas estratégias ainda permaneceram. Ocorreu, todavia, uma modificação importante no modo de alocação do apoio do professorado quando a reestruturação planejada para os aparelhos públicos de ensino tomou a forma de lei. Isso levou à reforma das práticas e estruturas precedentes através da confrontação das diferentes expectativas suscitadas pelo anúncio da transformação do funcionamento institucional da escolarização.

Na situação produzida após a discussão e aprovação da lei de reforma, a Diretoria-Geral de Instrução agiu imediatamente no sentido de decidir a partida. Fez dos cursos de conferências para professores e da elaboração dos programas das escolas primárias meios de divulgação da própria reforma. Isto não só foi fundamental para proporcionar outros parâmetros para a prática do ensino, mais de acordo com as expectativas dos reformadores, como sustentou as críticas às ações contrárias, anômalas ou transcendentes, à nova ordem de representações desejada. No interior dessa estratégia de confronto a construção do significado da designação escola nova foi também a construção de outras normas para a ação.

De fato, no Distrito Federal, a designação escola nova passou a suscitar 106 interesse no professorado a partir do patrocínio oficial da Diretoria-Geral de Instrução Pública. Foi o Curso de Conferências organizado, nos meses de abril e maio de 1928, para a divulgação da reforma da instrução, a ocasião escolhida para provocar a aproximação entre os princípios, as técnicas e as práticas do que se vinha chamando por toda a Europa de educação nova e as expectativas de renovação do sistema escolar da capital federal. Escola Nova foi o título utilizado por Manoel Bergströn Lourenço Filho para uma de suas duas conferências. Nela, tomou a escola nova como um processo de educação moderno, renovado a ponto de resolver as contradições entre o que havia de arte e de ciência na pedagogia. Foi o que, ao encerrar o curso, José Getulio Frota Pessoa reivindicou como conquista da reforma Fernando de Azevedo:

(...) Partindo de novos processos didáticos, a escola nova irradia no ambiente social, não como uma força solitária ou estranha que o agita, para modificá-lo ou corrigi-lo, mas como uma força intrínseca, que não se diferencia dele, senão pela sistematização, mas que com ele se confunde pelos métodos de ação e pelos objetivos a que aspira. Ela educa, como a própria vida educa ${ }^{21}$.

Lourenço Filho e Frota Pessoa ofereceram ao professorado uma nova referência de trabalho. A escola nova tornou conhecidas exigências de métodos; ambições de educação e decoro ao lado do senso de praticabilidade e racio- 
nalidade. No conjunto, o Curso de Conferências proporcionou a oportunidade de distinguir um conjunto de preocupações sociais (regionalismo, organização do trabalho), métodos de ensino (centros de interesse, escola do trabalho, método de projetos) e critérios de avaliação (testes pedagógicos e psicológicos) valiosos para formar um significado para a designação escola nova junto ao professorado.

Um novo lance ainda seria realizado. Em 1929, a Prefeitura do Distrito Federal publicou os Programas para os jardins de infância e para as escolas primárias, com introdução do diretor-geral da Instrução, Fernando de Azevedo. Nele, Fernando de Azevedo procurou criar uma representação unitária e singular da reforma da instrução que, utilizando os princípios da escola nova, tivesse o propósito de dar à escola uma consciência profunda de sua tarefa social e nacional e de a aparelhar dos meios necessários à realização dessa tarefa ${ }^{22}$. Entretanto, é na organização dos conteúdos, na distribuição das disciplinas, nas indicações metodológicas e nas sugestões para o plano de aula que se pode ter uma idéia mais precisa do significado dado à escola nova nesse documento. Trazia não só uma grade de disciplinas organizada por seus princípios educativos - observação, expressão, educação social e higiênica, história pátria e iniciação matemática - como um plano esquemático para o ensino de conjunto, repartido em três conjuntos temáticos especialmente interessantes à reforma da instrução: a natureza e o homem; o trabalho; e a sociedade. Havia instruções acerca das melhores estratégias de se aproveitar as oportunidades abertas pelas crianças para identificar-lhes o interesse, bem como indicações acerca do modo como orientar cada uma das disciplinas. No conjunto, discriminavam-se as normas através das quais procurava-se instituir os princípios da escola nova na atividade diária da classe.

O Curso de Conferências e os Programas puseram em cena a escola nova. $\mathrm{Na}$ feliz apreciação de Clarice Nunes, produziram representações sobre o lugar da escola nova, sua natureza e as possibilidades e limites das ações em seu nome engendradas ${ }^{23}$. Visaram a um intento pedagógico claro: tornar a aprendizagem uma atividade experimental. É por meio do movimento, da ação, da observação, da experimentação, da prática e da participação que os enunciados acerca da escola nova encontram um sentido pleno, uma significação positiva. Enfim, tratou-se de um movimento de atualização das práticas pedagógicas, da organização escolar e mesmo da compreensão acerca das possibilidades e finalidades da educação. Em parte, o vigor das práticas escolanovistas era sua reação contra uma escola imediatamente associada ao ensino das elites. A escola fundada em 1889 por Cecil Raddie em Derbisshire, Inglaterra, sob a denominação de New School, foi sobretudo uma resposta aos problemas enfrentados pelas Public Schools britânicas na educação das classes po- 
pulares. Entretanto, os grandes divulgadores da expressão parecem ter sido os suíços. Em 1909, Ferrière publicou um livro intitulado Projeto de Escola Nova, no qual tece considerações sobre as novas orientações educacionais que as instituições escolares deveriam atender. Foi, entretanto, somente depois da Primeira Guerra que o termo tornou-se de uso corrente, em especial devido à sua utilização por H. Pierre Bovet, diretor do Instituto J.J. Rousseau, no artigo que escreveu para o Intermediare des Educateurs intitulado "La tache nouvelle de l'ecole".

Por outro lado, no Brasil, o problema do escolanovismo não parece ter sido o de constituir uma teoria pedagógica que teria por função fazer o que John Dewey ou Adolf Ferrière quiseram fazer: investigar novos parâmetros, científicos ou filosóficos, para a prática pedagógica. Ao contrário, sua questão foi, essencialmente, tornar as representações sociais dos intelectuais com condições de reformar o sistema público de ensino mais adequadas ao trabalho com a educação e pouco comprometidas politicamente, o que, entretanto, não implicou tão-somente uma tarefa pedagógica, mas sobretudo política. E sob este aspecto, não o movimento de idéias, mas os homens responsáveis pelas reformas do ensino tinham um objetivo nítido: criar um sistema de educação concebido para a preparação eficaz da criança ao trabalho produtivo e atender às necessidades daquilo que esses intelectuais classificavam de um povo em formação, ou seja, tratava-se de um sistema de educação capaz de assegurar a coesão política e consolidar a composição étnica heterogênea do brasileiro.

Ocorre que o escolanovismo na pedagogia não foi imposto por Fernando de Azevedo por intermédio da sua reforma do ensino, nem por Lourenço Filho com seus livros ou conferências. Não foram também as associações de educação, notavelmente a Associação Brasileira de Educação (1924) e a Federação Nacional das Sociedades de Educação (1929) que o impuseram. Entretanto, ele se realizou porque respondia ao objetivo urgente de formar trabalhadores, assegurar a coesão política e consolidar a composição étnica do brasileiro. Portanto, o objetivo existia, havia um programa, e a estratégia desenvolveu-se com uma coerência e unidade cada vez maiores, mas sem que se deva supor uma homogeneidade de pensamentos ou de posições articulando-a sob a forma de um poder onipresente capaz de enunciar "isto é, isto não é escola nova”.

Há conseqüências. Que me seja permitido, sem visar a uma exaustividade ilusória, matizar os desdobramentos dessa ambigüidade a partir de duas análises significativas. Em sua rica síntese Educação e sociedade na Primeira República, Jorge Nagle oferece uma interpretação do escolanovismo inteiramente comprometida com o investimento técnico que o movimento repre- 
sentou para a história da educação brasileira. Não por outro motivo ela reduz o escolanovismo a um aperfeiçoamento dos aspectos internos da escola, uma linguagem que serviu como instrumento de comunicação de clichês, sendo incapaz de provocar a elaboração de meios eficazes que permitissem transformar os recursos programáticos da escola pública. De qualquer modo, há uma análise a ser recuperada a respeito do modo como esse "instrumento de comunicação de clichês" foi empregado. Jorge Nagle entende da seguinte forma a utilização desse novo esquema doutrinário:

(...) Os novos esquemas doutrinários se diferenciam daqueles empregados anteriormente pelo fato de não serem, simplesmente, enunciados gerais retirados da doutrina do republicanismo ou do ideário democrático. Antes de tudo, em lugar de partir deles para daí retirar as conseqüências para as instituições escolares, parte-se das idéias que se deve ter destas instituições - enquanto consideradas outras tantas instituições sociais - e do modo como devem funcionar num regime republicano e democrático ${ }^{24}$.

Ou seja, para Jorge Nagle, a escola nova emerge ao pensamento pedagógico brasileiro como um novo modelo de estruturação das instituições e orientação das práticas escolares. Isto fez com que coincidisse num mesmo momento a especialização técnica da pedagogia e a pressão sobre a estrutura do Estado no sentido de ampliar suas funções quanto aos serviços educacionais. A educação, nesse movimento, passou a interessar ao próprio funcionamento do Estado: por isto mesmo, disse Jorge Nagle, serão no âmbito das administrações escolares que vão ser observadas muitas transformações; nelas, por exemplo, altera-se o modo de encarar o ensino primário, que sofre mudanças de natureza qualitativa depois de passar por um período de desenvolvimento quantitativo ${ }^{25}$. Insistirei ainda num ponto desta interpretação. Ela distingue da experiência de reforma na constituição de um novo modelo para o sistema público de ensino o processo de formação de uma categoria especial de profissionais, os educadores. Assim, a análise de Jorge Nagle acerca do aparecimento do técnico em escolarização aponta que o Estado dispõe de especialistas autorizados a modificar-lhe o sistema administrativo, mas silencia sobre os recursos utilizados para que tais especialistas possam operar com segurança e proteção. Creio que é justamente aí que se pode especular sobre a função política desempenhada pelo escolanovismo.

As pesquisas realizadas por Marta Carvalho acerca da constituição de um campo especializado para a atuação dos educadores apontam para um processo de natureza diferente. Ela entende a figura do técnico em educação como um dividendo político do jogo oligárquico republicano. Este modo de 
compreender a mudança no trato das questões educacionais ocorrida com o trabalho de homens públicos comprometidos com a institucionalização do sistema escolar sinaliza para a coincidência entre as estratégias utilizadas para promover a reforma da escola e os intentos políticos dos governos estaduais:

(...) Na situação da crise oligárquica, abrir espaço para a intervenção técnica dos profissionais da educação, esses mediadores do moderno que surgiram na cena pública na década de 20, era fato político de impacto que sacudia a rotina administrativa e projetava os seus promotores no cenário nacional da disputa oligárquica ${ }^{26}$.

A idéia que resulta dessa interpretação recoloca o campo de atuação dos profissionais da educação no cenário político da época. Em lugar do domínio técnico é a polêmica política que anima a discussão educacional do período. E tanto na polêmica política quanto na discussão educacional trabalhou-se para tornar a promessa de modernização social, política e econômica parte do jogo oligárquico:

(...) Nesse jogo oligárquico são os governantes de São Paulo, direta ou mediatamente por meio de seus representantes na Presidência da República, que distribuem benesses a seus aliados eleitorais. Punham à disposição os seus técnicos, homens cuja experiência na institucionalização do sistema escolar paulista os havia credenciado como portadores de um saber vazado nos preceitos da pedagogia moderna ${ }^{27}$.

Esse contexto permite falar do escolanovismo de uma maneira diferente: não mais como modelo de estruturação do sistema escolar, mas como um meio de ajustar os homens às condições e valores da vida moderna. O deslocamento é substancial quando se pensa nas suas conseqüências. Ele transfere o problema da educação popular para uma região que apanha simultaneamente a técnica e a política. A análise de Marta Carvalho acerca do lugar ocupado pelos "técnicos" da educação no jogo oligárquico indica a região que o tema da educação popular passa a ocupar com as reformas da instrução pública na capital federal, qual seja, a das apostas numa sociedade nova, moderna, planejada e organizada em função da ciência e da ordem política democrática. Mas, ainda aqui, a especulação acerca da função política que desempenhou o escolanovismo fica mal resolvida. A contribuição que Marta Carvalho dá à questão determina de modo convincente os limites da implementação política desse programa de redefinição das práticas educativas em seus princípios e processos, sem contudo problematizar a importância técni- 
ca que esse mesmo programa assumiu na recomposição do sistema público de ensino realizada pelas reformas republicanas da instrução.

A desmontagem do programa escolanovista por parte da historiografia da educação concentra sua crítica particularmente no modo como as reformas da instrução pública encaminharam a realização das suas finalidades práticas. Dessa perspectiva, a revisão que se fez da história do período nos últimos anos foi capaz de converter o conteúdo político das reformas da instrução pública em ponto de partida analítico dos pressupostos técnicos da escola no$v a$. Não foi pouco, mas houve um preço: ainda não há preocupação com o modo como as intenções técnicas se tornaram uma questão política fundamental para as reformas da instrução pública.

Também não é a minha intenção investigar essa questão aqui. Desejo apenas mostrá-la como a outra forma dos debates pedagógicos do período para poder analisar a ambigüidade do escolanovismo como intento pedagógico e lance político dos responsáveis pelas reformas da instrução pública na cidade do Rio de Janeiro. Será preciso, entretanto, tomar aquilo que penso ter ocorrido de forma simultânea separadamente a fim de dar clareza aos argumentos. A escola nova encarnou o programa de ação educacional elaborado e planejado por intelectuais com reconhecida autoridade técnica. Por isso foi múltiplo, apareceu num só tempo como programa pedagógico na resolução de questões técnicas em educação, do modo em que aparece no livro de Lourenço Filho Introdução ao Estudo da Escola Nova, mas também nos programas escolares editados por Fernando de Azevedo; como programa de idéias e ações sociais na consolidação de um modelo de escolarização centrado no princípio do trabalho educativo quando da implementação dos novos programas escolares por parte de Carneiro Leão ou, mais ousadamente, por ocasião da reorganização do sistema público de ensino entre 1928 e 1930, fruto da manobra política da reforma da instrução elaborada por Fernando de Azevedo para legitimar as iniciativas de implementação do novo código de lei; e enfim, como programa de regulação social diante dos problemas de governabilidade enfrentados pela administração pública da capital federal.

Assim, em primeiro lugar, nota-se o acabamento técnico com que os textos oficiais apresentaram seu programa pedagógico. Os métodos ativos, tal como aparecem nos programas escolares de 1926 e de 1929, reivindicavam um ensino prático e útil, capaz de assegurar uma eficiente adaptação da criança ao meio social de que ela provém. Para além dos esquemas didáticos, das justificativas metodológicas e das finalidades pedagógicas existiu neles uma notável preocupação evolucionista. Superficialmente, pode-se percebê-la na insistência com que a psicologia foi evocada para determinar os processos de diferenciação das capacidades cognitivas em cada fase da vida e entre cada in- 
divíduo; falava-se em feição psicológica preponderante, e os movimentos de organização hierárquica, nos quais preponderava a psicologia experimental, tinham por função fornecer ao professor os elementos para avaliar em linhas gerais a capacidade do aluno e até onde era possível chegar com cada um.

Um tanto menos evidente foi o comprometimento que a sociologia teve com essas preocupações. Entretanto, é ainda nos programas escolares que se pode perceber a influência que o pensamento sociológico exerceu na reorganização das práticas escolares de educação. No empenho em formar bons cidadãos, presente nas indicações de integração das disciplinas, era legível a atenção com que, por meio do entendimento sociológico, se procurou consolidar uma unidade comunitária, educar os sentimentos da criança em relação aos símbolos nacionais e sugerir que dos destinos da nação no curso da sua história dependia o próprio destino do indivíduo no curso de sua gênese psicológica. A evidência dos cuidados observados pelos programas escolares com as características biológicas das crianças, nos aspectos de saúde, constituição física e desenvolvimento psicológico, completa o quadro que serviu de cenário ao sistema filosófico de Spencer em que os princípios de psicologia são precedidos pelos princípios de biologia e sucedidos pelos princípios de sociologia.

112 Conforme montado nos programas escolares, tratou-se de um cenário menos determinista, mas não menos determinado na sua finalidade: civilizar. Suas bases estiveram fincadas na preocupação com a sobrevivência do brasileiro, com a evolução da sua cultura e com as características da sua nacionalidade. Em poucas palavras, com o destino social da população brasileira. De certa maneira, enquanto estiveram em vigência, os programas escolares movimentaram representações acerca do progresso. Eles responderam a um modelo de progresso social e cultural orientado especialmente a ciência, o industrialismo e a democracia. Dessa perspectiva, o evolucionismo cumpriu uma função importante na definição dos conteúdos escolares ao fazer deles um domínio prestigiado na conformação da personalidade, dos sentimentos, das vontades, da memória e dos hábitos.

Depois, é nítido o programa de reformas sociais postulado pelas reformas da instrução pública. Tanto Carneiro Leão quanto Fernando de Azevedo lidaram com dispositivos de poder já disseminados pela sociedade; a originalidade de suas reformas encontra-se, portanto, no modo como investiram, nesses dispositivos, e como os utilizaram, transformaram ou deslocaram no espaço escolar. Se as resoluções obtidas por Carneiro Leão e Fernando de Azevedo foram diferentes, suas motivações foram comuns. Defrontaram-se com o problema da acumulação populacional. Escolarizar era educar as massas: foi a idéia de uma escola para as massas que preencheu os discursos acerca da 
educação popular com seu conteúdo político. Seu significado foi evidente para os intelectuais que se ocuparam com os negócios da instrução pública _tratava-se de fazer da escola mais um mecanismo que permitisse a regulação das relações sociais, mais um dispositivo de controle das suas oscilações (revoltas, greves, motins e manifestações partidárias) e irregularidades (sobretudo a marginalidade). O problema disciplinar expressado por ambas as reformas da instrução não era o da punição, mas o de impossibilitar uma má ação. Ponto fulcral da questão foi o investimento em mecanismos sutis de disciplina capazes, no entanto, de interiorizar as "boas" normas da conduta na criança. Foi por meio da idéia de "autogoverno" que se encaminhou a questão. Atividades e lições de cunho moral, vigilância e inspeção regulares mobilizaram o corpo infantil no exercício diário do autocontrole de si e na aprendizagem dos comportamentos socialmente valorizados.

Essa forma de disciplina desempenhou um papel importante na solução de um outro problema para o bom funcionamento da cidade, a moralização dos operários. Para tanto, recorreu-se aos dispositivos de saúde e de bem estar físico: o tratamento médico e dentário, o respeito às regras gerais de higiene, a orientação profissional, a manutenção da ordem disciplinar e a assistência das caixas escolares proveram a escola de um conjunto de regulamentos e instituições próprias para organizar não apenas a sujeição do indivíduo, mas principalmente o aumento de sua utilidade.

Havia ainda um outro problema: tornar a escola um fator substancial ao desenvolvimento da força produtiva. Buscou-se com insistência suprir a escola com dispositivos capazes de fixar os pobres aos aparelhos de produção. No ensino profissional sobretudo, mas também nas escolas primária e normal, ocorria uma intensificação dos enunciados acerca do trabalho. Nas escolas profissionais a idéia de formação do operariado, na escola normal a diminuição do curso propedêutico em comparação com o programa de preparação profissional das professoras, na escola primária a idéia de trabalho educativo constituía os elementos principais de um aparelho de educação direcionado ao ensino vocacional. $\mathrm{E}$, finalmente, a organização de um sistema de ensino público capaz de solucionar todos esses problemas. Foi esse o grande lance político das reformas da instrução pública na década de 1920. Tornar o sistema público de ensino a principal trincheira de um programa de intervenção social.

Finalmente, houve nisso tudo um claro esforço de regulação social. Em documentos oficiais ou em pronunciamentos públicos os reformadores insistiram em sublinhar o modo como entendiam a relação existente entre a autonomia do indivíduo e a administração pública. Em relatório escrito em 1925, Carneiro Leão diz o seguinte: “A geração que está nas nossas mãos será 
aquilo que nós a fizermos. A sua possibilidade advirá, diretamente, da nossa maior ou menor generosidade em prepará-las para a luta pela vida." ${ }^{28}$ Foi esse vínculo de sobrevivência que ele entendia caber à escola regular. Nesse sentido, foi pela formação das crianças que Carneiro Leão pensava convencer a administração pública da função desempenhada pela escola na instrumentalização do poder de governabilidade.

Fernando de Azevedo, em discurso no Jockey Club, pronunciado dois anos mais tarde, revisitaria o tema de um modo exemplar. Para ele seria tarefa da instrução fazer com que as relações entre a autonomia do indivíduo e a administração pública fossem determinadas a partir de uma identidade social de natureza profissional. Assim, a instrução pública encontraria o seu fim principal: "enraizar o operário às oficinas, o lavrador à terra e o pescador às praias" 29 . Por meio dessa fórmula Fernando de Azevedo entendeu poder não só tornar a escola pública economicamente vantajosa, evitando o deslocamento das populações por meio da adaptação do trabalhador ao meio no qual se criou e se educou, como também politicamente útil, uma vez que alçava mira contra tudo aquilo que estivesse fora da esfera do trabalho. Em última instância, foram o meio familiar, a comunidade e a profissão os canais por que a reforma Fernando de Azevedo procurou dimensionar as relações entre o indivíduo e o Estado.

Em todas essas ocorrências, o que se observa é o liame do técnico com o político no domínio das questões educacionais constitutivas do campo de atuação dos educadores profissionais na década de 1920. A montagem de um sistema de ensino integrado na capital do País _ capaz de conduzir a criança sem saltos ou deficiências aos níveis mais adiantados da escolaridade _ foi o papel essencial de que se investiu a reforma Carneiro Leão. E se foi assim entre 1922 e 1924, também o seria na administração seguinte, como atesta o discurso de posse de Fernando de Azevedo, que diz basicamente: as instituições de ensino não devem dissimular através de sua variedade orgânica e funcional as relações recíprocas de coordenação para um objetivo comum ${ }^{30}$. É outra vez a idéia de sistema que domina: a harmonia de um sistema de construção, dizia Azevedo.

É essa idéia que repercute nas iniciativas da remodelação do aparelho escolar. Nem sempre confessada, mas insistentemente presente, ela reivindicou uma direção precisa para a reforma do ensino: uma organização pedagógica modelar. É dizer: submeter o aparelho de ensino a uma ordem de funcionamento. No caso, optou-se pelas funções sociais. Foi este também o sentido da manobra realizada pelas reformas do ensino entre 1922 e 1930 para legitimar seu programa de ação. Nessa direção concorreram tanto os novos programas de ensino primário quanto as iniciativas assistenciais, as orientações discipli- 
nares, a construção de prédios escolares, a reforma do ensino normal e profissional, a remodelação da inspeção médica, a organização dos pelotões de saúde, dos museus escolares, do escotismo, e a introdução do cinema educativo. Sublinhe-se somente o seguinte: as finalidades educativas e sociais da escola comportaram um programa bastante nítido de formação cívica e modelação moral que significou não só a confirmação de uma identidade coletiva, mas também a moralização da classe operária. Tem-se aí o cerne do modelo de escolarização que se quis implantar no Distrito Federal sob a designação de escola nova.

CiVILIZAÇÃO, PROGRESSO E MODERNIDADE:

A REESTRUTURAÇÃO DO SISTEMA PÚBLICO DE ENSINO COMO TAREFA DAS REFORMAS DA INSTRUÇÃO

A temática da educação popular e da escola nova ficou ligada a textos hoje clássicos de Fernando de Azevedo, Lourenço Filho e Anísio Teixeira. Essa temática, própria da visão dos responsáveis pelas reformas da instrução pública durante as décadas de 1920 e 1930, oferece uma perspectiva do entendimento que tiveram das possibilidades e limites da reforma pedagógica. É possível, de fato, extrair muitos materiais e reflexões de livros como Novos caminhos e novos fins, Introdução ao estudo da escola nova ou Educação progressiva. Atualmente, entretanto, convém citá-los mais para indicar quanto as disputas em torno de uma escola pública, gratuita, leiga e única corresponderam, sobretudo, à realização de um ideal de formação alimentado pelo desejo de atualizar o sistema produtivo nacional

O caminho brasileiro para a sociedade industrial tem início numa excrescência da idéia de progresso econômico e social: a idéia de atraso. O que se procurou formar e orientar em textos como os citados acima foi tarefa ilimitada de articular as condições para pôr o Brasil em dia com a história codificada pelas nações mais avançadas, de "resolver os impasses da não-contemporaneidade", segundo o pensamento de Octavio Ianni ${ }^{31}$. O empreendimento deixou as diversas fontes com que lidei neste texto, relatórios administrativos, monografias descritivas, documentos estatísticos, correspondência oficial, artigos de periódicos, relatos de reforma e compêndios de pedagogia. $\mathrm{Ne}$ las pareceu-me tão legítimo reconhecer os recursos mobilizados quanto as aspirações motivadoras; não foram somente com as publicações, as construções, as conferências e todos os demais investimentos feitos para reformar o funcionamento do sistema público de ensino carioca que se enfrentaram os riscos da transformação cultural. Também foram canalizadas idéias para a 
educação da população. E sob a designação escola nova escondeu-se uma delas: a de que uma infra-estrutura escolar bem diferenciada e saturada, quanto aos níveis do ensino e ao número e à qualidade das escolas, e bem distribuída pela cidade, atendendo a todos os setores da população, constituiria a base segura para a reorganização nacional, da cultura nacional, fonte da civilização que se procurava erigir nos trópicos. A ela respondeu o esforço educacional despendido pelas reformas da instrução durante o período.

Disso beneficiaram-se as políticas públicas de educação desenvolvidas por Carneiro Leão e Fernando de Azevedo. Suas facetas são bem conhecidas. Em uma enumeração ligeira, quiseram garantir: a) o crescimento das oportunidades educacionais dentro dos quadros da instrução pública, para taxas capazes de assegurar a extração mais adequada de quadros competentes para a direção política ou para as empresas; b) a diversificação da mão de obra semi-especializada ou mais qualificada, decorrente da aceleração do progresso urbano e industrial ocorrida em meio à traumática trajetória de sustentação do café e das divisas e seu posterior declínio; c) os vários requisitos educacionais propagados pela moderna pedagogia; a ênfase dada ao trabalho que ajuntou aos valores básicos da educação a racionalidade e a eficiência; d) uma súbita ligação entre os conteúdos da aprendizagem com as orientações concretas 116 do comportamento social, da vida econômica ou da representação política, como forma de impor uma educação plástica e dinâmica; e) a consolidação dos valores nacionais dentro do horizonte cultural médio, algo incipiente mas fundamental, pois as transformações sociais acarretadas com a modernização capitalista punham em tensão formas contraditórias de responsabilidade individual e coletiva, de autonomia da pessoa e de disciplina coletiva, de fruição da vida e de altruísmo, e de flexibilização das relações entre as gerações e de distanciamento social e cultural entre elas.

As discussões acerca do alcance das reformas da instrução pública realizadas na década de 1920 encontram aí matéria para um bom debate. Os êxitos foram restritos, entretanto, devem ser avaliados mais pelos seus indícios que pelos seus índices. Separando-se os avanços qualitativos dos índices quantitativos é possível sublinhar, e mais fácil compreender, a influência política das reformas Carneiro Leão e Fernando de Azevedo na consolidação de um projeto de democratização escolar através do Estado. As fontes de que me utilizei para estudar essas duas reformas insistem em divulgar, mais que os resultados obtidos, as operações efetuadas para assegurar o aproveitamento dos recursos educacionais em todos os níveis da escolarização municipal, propagando a contraparte qualitativa dos limites quantitativos. De modo mais objetivo é dizer que, dos problemas enfrentados para a implementação das reformas da instrução pública, o elemento principal na produção desses 
documentos foi político: engajar o aparelho de Estado na obra de reconstrução educacional. Era o modo de assegurar a autoridade e os recursos orçamentários necessários à difusão do ensino:

(...) Não é, pois, uma frase oca, a afirmação de que o dever supremo da República é a educação primária integral. Além de um dever, é o seu maior interesse. Verdadeiramente, a educação é, para os governos, um alto negócio. A opulência dos cofres públicos está na proporção direta da capacidade produtiva do povo. O que a uma nação mais importa não é a massa, volumosa e inerte, dos seus habitantes. Mas a capacidade criadora de seus homens ${ }^{32}$.

São as implicações dessa orientação que cumpre sublinhar. Confrontando as informações utilizadas por Antônio Carneiro Leão e Fernando de Azevedo para a divulgação e propaganda dos resultados obtidos por suas respectivas reformas, é possível identificar algumas manobras comuns e um investimento administrativo reiterado na fixação gradual de normas e objetivos efetivamente comprometidos com a expansão do ensino. Mesmo limitadas, transversais, parciais, porquanto cercadas por regiões de opacidade onde todo trabalho de elaboração produziu resultados imprevistos àqueles mesmos que o planejaram, essas manobras foram lances de astúcia na tentativa de assentar socialmente a possibilidade de uma nova escola. Não por acaso, entre 1928 e 1930, tanto quanto as experiências que Carneiro Leão conduziu na reforma da instrução entre 1922 e 1926 para disseminar os métodos ativos, os esforços no sentido de se divulgar uma versão de reforma do trabalho educativo como escola nova constituíram-se fundamentalmente a partir do trabalho legislativo, da captação de recursos orçamentários e do controle doutrinário da prática docente.

Por essa perspectiva parece oportuno finalizar organizando o que ficou dito aqui acerca dos modos pelos quais as reformas da instrução pública intervieram nesses domínios da gestão do sistema escolar.

É conveniente começar pelo trabalho legislativo. Isto porque converter o Estado republicano num instrumento de reforma social configurou-se uma tarefa eminentemente legislativa. As reformas da instrução pública realizadas no período foram uma amostra disso. Tanto em 1924 quanto em 1928 responderam aos anseios de reforma social de parte das elites intelectuais residentes na capital do País com um novo código de lei para o ensino. No primeiro caso, ele seria rejeitado pelo Conselho Municipal, o que não impediu a reforma, ela se expressaria por outros regulamentos _ notavelmente os programas escolares. No outro caso, o Decreto n. 3.281 de 28 de janeiro de 1928 fez crer nas possibilidades de uma instrução pública não estorvada por expe- 
riências de prática política, nomeações e prerrogativas administrativas principalmente. Nele dominou a perspectiva de uma política de educação de perfeição última e estável, um código de lei no qual os vigamentos para a modernização da ordem social poderiam ser visualizados.

Ambas as reformas da instrução incorporaram as ambições legisladoras às suas intenções de planificação, e seus responsáveis estiveram convencidos de que assim como havia uma moralidade pública a ser respeitada pelo zelo remodelador do departamento de instrução, havia um novo instrumental a ser assimilado no trabalho legislativo de normalização do trabalho educativo. As disputas pelo controle da norma não serviram, entretanto, somente para assegurar a licença incontestada da autoridade pública para impor obediência ao programa de reformas, mas sobretudo serviram para permitir decisões ad hoc capazes de evitar, ou enfrentar, os desafios lançados contra a ordem estabelecida.

O orçamento foi outro front de manobras comum. Os dados com que a administração Antônio Carneiro Leão trabalhou indicavam uma necessidade elevada de investimentos no setor educativo. De 1917 até 1925, a razão percentual entre a verba destinada ao ensino primário em relação à renda geral da municipalidade decresceu 9 pontos. Era de 20,3 em 1917. Passou a ser de $118 \quad 11,5$ em $1925^{33}$. Por outro lado, era a expansão da capacidade de atendimento do sistema público de ensino a alça de mira das reformas da instrução no período. Esta foi a contradição fundamental enfrentada tanto por Carneiro Leão quanto por Fernando de Azevedo: a estagnação do investimento público no momento de triunfo de uma política de educação que objetivava viabilizar a expansão da infra-estrutura escolar necessária à rearticulação do sistema de ensino. A superação dessa restrição implicaria um esforço político no sentido de conseguir junto aos Poderes Executivo e Legislativo e dos setores particulares do Distrito Federal a liberação de recursos orçamentários necessários para a reestruturação educacional. Ele esteve relacionado ao esgotamento da capacidade instalada do aparelho escolar da capital, o que requeria recursos e capacidades para redesenhar a rota de expansão da instrução pública.

O trabalho de racionalização, remanejamento e realocação dos recursos disponíveis e orçados para a educação na cidade do Rio de Janeiro, feito por Carneiro Leão, foi tido como o indicador definitivo desse esgotamento. Desse modo, a influência de Fernando de Azevedo junto ao Executivo municipal pareceu decisiva na alocação de recursos extras para a ampliação do quadro funcional da Diretoria de Instrução e da equipe de inspeção, para a liberação das verbas necessárias à construção de sete novos edifícios escolares e a reforma de outros dois, para a instalação de uma Clínica Escolar num dos distritos escolares da cidade, e do Almoxarifado-Geral da Instrução em São Cris- 
tovão. Em ambos os casos, as discussões em torno dos recursos necessários à expansão do sistema de ensino público tiveram, nesse período, um implemento qualitativo: questionavam sobre os custos integrais da regulamentação de suas políticas educacionais.

Havia ainda uma dimensão menos quantificável mas igualmente importante: o refinamento intelectual, o espírito criativo e a qualidade política das respostas educacionais às exigências da modernização tecnológica. Nas reformas da instrução aparecia com nitidez o pensamento de que a atualização e vitalização do sistema público de ensino dependiam de uma nova forma de orientar e calibrar a modernização das instituições-chave do aparelho pedagógico, isto é, da Diretoria-Geral de Instrução, das escolas primárias, das profissionais e da Escola Normal. Essa diretriz avançou até a consolidação de um ideário de reforma. Nesse particular o escolanovismo cumpriu um papel especial, mostrou que a educação pública não era apenas estrutura que se difunde, mas uma significação que se constrói.

A preocupação de ajustar a diferenciação e a qualidade do ensino aos requisitos de uma civilização urbano-industrial, e também o anseio de considerar a produção intelectual dos educadores, em particular a resultante da pesquisa científica, a serviço de um sistema de educação pública, deu importância às reformas da instrução. Sob a designação escola nova, tanto as preocupações quanto os anseios daqueles que participaram das campanhas de renovação educacional encontraram uma valência comum. Ela foi toda feita na aproximação de intelectuais identificados com o movimento de inovação educacional e professores interessados nessa renovação: é dizer que se estruturou ao redor de alguns grandes temas e de alguns nomes destacados ${ }^{34}$. Nesse sentido, a significativa produção intelectual, as reformas da instrução e os movimentos de reorganização de instituições escolares, técnicas e administrativas consolidaram mais que um projeto definido de ação educativa, um sistema de alianças políticas.

Tais manobras raramente alcançaram um resultado uniforme. Acionaram um número elevado de questões para poder avançar de forma homogênea sobre os propósitos enunciados. Tenderam a justapor iniciativas localizadas mesmo quando o embate político reivindicava planejamento contínuo. Nisso refletiram muito as possibilidades abertas pelos quadros executivos da velha República na área da educação: articulação do que já existia, organização daquilo que ainda funcionava e a realização de empreendimentos cujos dividendos políticos eram coisa certa. Os seus promotores foram todos intelectuais e/ou professores que, aos seus próprios olhos, trabalhavam para o bem público. Não duvidaram que cada uma de suas iniciativas cumpria a tarefa de contribuir para transformar o aparelho escolar instalado para a ins- 
trução pública num sistema de escolarização ao alcance de todos, mas recusavam-se a expandi-lo sem reservas ou precauções. Em cada manobra que realizaram na Diretoria-Geral de Instrução enunciavam essa tarefa como parte da obra de regeneração/reorganização/reconstrução nacional.

Tal imperativo explica muito do apoio das autoridades públicas ao programa de reformas reivindicado por esses intelectuais e professores, o que não significou, entretanto, investimento pecuniário ou prerrogativas políticas acentuadas no interior da máquina administrativa para o setor educacional. As reformas da instrução ali organizadas foram naturalmente tributárias das necessidades, dos meios e da eficácia de uma administração que, na prática, permanecia subequipada para patrocinar reformas de qualquer tipo ou natureza $^{35}$. Identificadas com as ações dos inspetores de ensino, dos professores da Escola Normal e da equipe técnica do departamento de instrução da Prefeitura, as reformas do ensino foram, por outro lado, suspeitas aos olhos de muitos, professores primários, imprensa, partidos políticos e parte da população, sendo freqüentemente objeto de táticas de evasão que lhe limitaram ainda mais o alcance.

Postas nestes termos, as reformas da instrução pública em nenhum momento conseguiram mobilizar seus recursos materiais e humanos numa es120 cala de eficácia máxima. É certo que a ambição de reformular as condições de administração do ensino público produziu, por um lado, o aumento da especialização dos saberes pedagógicos, e por outro, o aumento da autoridade da ciência, o clima mental de racionalidade afeito àa factibilidade técnica e ao aproveitamento da disponibilidade de recursos subaproveitados. Entretanto, teve de enfrentar formas tão extremas de desigualdade econômica e sociocultural que repercutiu pouco para a implementação dos requisitos educacionais vistos como necessários à integração da sociedade nacional e à aceleração do seu progresso. Ainda assim, é prudente reconhecer nas manobras que logrou realizar as implicações construtivas das reformas de instrução pública na capital federal para a modernização tanto da linguagem como da infra-estrutura escolar do País.

\section{NOTAS}

${ }^{1}$ NUNES, Clarice. "História da educação brasileira: novas abordagens de velhos objetos." Teoria \& Educação, no 6, pp. 151- 181, 1992.

${ }^{2}$ VIDAL, Diana Gonçalves. O exercício disciplinado do olhar: livros, leituras e práticas de formação docente no Instituto de Educação no Distrito Federal (1932-1937). São Paulo: FEUSP, 1995. Tese de doutorado. 
${ }^{3}$ NAGLE, Jorge. Educação e sociedade na Primeira República. São Paulo: EPU; Rio de janeiro: Fundação Nacional de Material Escolar, 1974, p. 108.

${ }^{4}$ PAIVA, Vanilda Pereira. Educação popular e educação de adultos: contribuição à história da educação brasileira. São Paulo: Edições Loyola, 1973, p. 94.

${ }^{5}$ Idem, pp. 26-36.

${ }^{6}$ CARVALHO, Marta Maria Chagas de. Molde nacional e fôrma cívica: higiene, moral e trabalho no projeto da Associação Brasileira de Educação (1924-1931). Bragança Paulista: Edusf, 1998, p. 38.

${ }^{7}$ MONARCHA, Carlos. A reinvenção da cidade e da multidão: dimensões da modernidade brasileira — a escola nova. São Paulo: Cortez, Autores Associados, 1989,p. 16.

${ }^{8}$ VOVELLE, Michel. Ideologias e mentalidades. São Paulo: Brasiliense, 1987, p. 41.

${ }^{9}$ COUTO, Miguel. “A educação popular.” Educação, v. X, no 5 e 6, Rio de Janeiro: Albuquerque Neves, 1925, p. 701.

${ }^{10}$ CARNEIRO LEÃO, Antônio. O Brazil e a educação popular. Rio de Janeiro: Typ. do Jornal do Commercio, 1917, p. 35.

${ }^{11}$ AZEVEDO, Fernando de. Da educação física: o que ela é, o que tem sido e o que deveria ser. São Paulo: Weiszflog irmãos, 1920, pp. 185-86.

${ }^{12}$ CURY, Carlos Roberto Jamil. Ideologia e educação brasileira: católicos e liberais. São Paulo: Cortez, 1978.

${ }^{13}$ CARVALHO, Marta Maria Chagas de. "O território do consenso e a demarcação do perigo: política e memória do debate educacional dos anos 1930.” In.: FREITAS, Marcos Cezar de (org.). Memória intelectual da educação brasileira. Bragança Paulista: Edusf, 1999, pp. 17-30.

${ }^{14}$ MAZZOTTI, Tarso Bonilha. Educação popular segundo os sindicalistas revolucionários e os comunistas da Primeira República. São Paulo: FEUSP, 1987. Tese de doutorado.

${ }^{15}$ CARVALHO, Marta Maria Chagas de. Molde nacional e fôrma cívica: higiene, moral e trabalho no projeto da Associação Brasileira de Educação (1924-1931). Op. cit. SOUZA, Maria Cecília Cortez Christiano de. Escola e memória. Bragança Paulista: Edusf, 2000. MONARCHA, Carlos. Op. cit..

${ }^{16}$ HILSDORF, Maria Lúcia. Francisco Rangel Pestana: jornalista, político, educador. São Paulo: FEUSP, 1986. Tese de doutorado, p. 111.

${ }^{17}$ BARROS, Roque Spencer Maciel de. A ilustração brasileira e a idéia de universidade. São Paulo: Universidade de São Paulo - FFCL, Boletim no 241, História e filosofia da educação nº 2, 1959, p. 203.

${ }^{18}$ AZEVEDO, Fernando de. A educação pública em São Paulo: problemas e discussões inquérito para “O Estado de S. Paulo”, em 1926. São Paulo: Editora Nacional, 1937, p. 8. 
${ }^{19}$ Idem. Novos caminhos e novos fins: a nova política de educação no Brasil. São Paulo: Editora Nacional, 1931, p. 118.

${ }^{20}$ CARNEIRO LEÃO, Antônio. A educação na capital do Brasil. Rio de Janeiro: Typ. do Jornal do Commercio, 1926, p. 44.

${ }_{21}$ "A reforma do ensino primario: suas caracteristicas fundamentaes", Jornal do Commercio, Rio de Janeiro, 2 jun. 1928.

${ }^{22}$ AZEVEDO, Fernando de. "A escola nova e a reforma.” In: PREFEITURA DO DISTRICTO FEDERAL. Programmas para os jardins de infancia e para as escolas primarias. Rio de Janeiro: Officinas Graphicas do Jornal do Brasil, 1929, p. 2.

${ }^{23}$ NUNES, Clarice. "A escola nova no Brasil: do estado da arte à arte do estudo.” In: GVIRTZ, Silvina (org.). Escuela nueva en argentina y Brasil. Buenos Aires: Niño y D’avila, 1995, p. 14.

${ }^{24}$ NAGLE, Jorge. op. cit., p. 196.

${ }^{25}$ Idem, p. 289.

${ }^{26}$ CARVALHO, Marta Maria Chagas de. "Reformas da instrução pública.” In: LOPES, Eliane Marta Teixeira; FARIA FILHO, Luciano Mendes de; VEIGA, Cinthya Greive. 500 anos de educação no Brasil. Belo Horizonte: Autêntica, 2000, p. 233.

${ }^{27}$ Idem, p. 234.

${ }^{28}$ CARNEIRO LEÃO, Antônio. O ensino na capital do Brasil.Op. cit., p. 214.

${ }^{29}$ AZEVEDO, Fernando de. A reforma do ensino no Districto federal: discursos e entrevistas. São Paulo: Melhoramentos, 1929, p. 43.

${ }^{30}$ Idem, p. 14.

${ }^{31}$ IANNI, Octávio. “Estilos de pensamento.” In: RUGAI BASTOS, Élide; MORAES, João Quartim (orgs.). O pensamento de Oliveira Vianna. Campinas: Editora da Unicamp, 1993, p. 430 .

${ }^{32}$ SAMPAIO DÓRIA, apud FROTA PESSOA, José Getúlio. A realidade brasileira. Rio de Janeiro: Francisco Alves, 1931, p. 172.

${ }^{33}$ CARNEIRO LEÃO, Antônio. O ensino na capital do Brasil. Op. cit., p. 21.

${ }^{34}$ SCHWARTZMAN, S.; BONEMY, H.M.B.; COSTA, M.V. Tempos de Capanema. Rio de Janeiro: Paz e Terra; São Paulo: Edusp, 1984, p. 52.

${ }^{35}$ FURTADO, Celso. A pré-revolução brasileira. Rio de Janeiro: Fundo de Cultura, 1962, pp. 78-9.

Artigo recebido em 11/2002. Aprovado em 10/2003. 